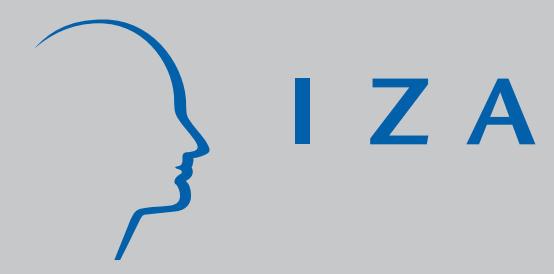

IZA DP No. 2521

Calvo Wages in a Search Unemployment Model

Vincent Bodart

Olivier Pierrard

Henri R. Sneessens

December 2006 


\title{
Calvo Wages in a Search Unemployment Model
}

\author{
Vincent Bodart \\ Université catholique de Louvain \\ Olivier Pierrard \\ Central Bank of Luxembourg \\ and Université catholique de Louvain \\ Henri R. Sneessens \\ Université catholique de Louvain, \\ Université catholique de Lille and IZA Bonn
}

\section{Discussion Paper No. 2521 December 2006}

\author{
IZA \\ P.O. Box 7240 \\ 53072 Bonn \\ Germany \\ Phone: +49-228-3894-0 \\ Fax: +49-228-3894-180 \\ E-mail: iza@iza.org
}

\begin{abstract}
Any opinions expressed here are those of the author(s) and not those of the institute. Research disseminated by IZA may include views on policy, but the institute itself takes no institutional policy positions.
\end{abstract}

The Institute for the Study of Labor (IZA) in Bonn is a local and virtual international research center and a place of communication between science, politics and business. IZA is an independent nonprofit company supported by Deutsche Post World Net. The center is associated with the University of Bonn and offers a stimulating research environment through its research networks, research support, and visitors and doctoral programs. IZA engages in (i) original and internationally competitive research in all fields of labor economics, (ii) development of policy concepts, and (iii) dissemination of research results and concepts to the interested public.

IZA Discussion Papers often represent preliminary work and are circulated to encourage discussion. Citation of such a paper should account for its provisional character. A revised version may be available directly from the author. 
IZA Discussion Paper No. 2521

December 2006

\section{ABSTRACT \\ Calvo Wages in a Search Unemployment Model}

RBC models with search unemployment and wage renegotiation generate too much wage volatility and too stable unemployment rate. Shimer (2004) shows that it is possible to reproduce a volatility of unemployment similar to that observed in actual economies by imposing full real wage rigidity. We use a similar model but with Calvo wage contracts and we obtain a microfounded equation of real wage rigidities. The models with full wage flexibility or full wage rigidity are obtained as particular cases. We show that a contract length of about six quarters fits best the observed cyclical properties of wages and unemployment.

JEL Classification: E24, E32, J30, J41

Keywords: $\quad$ search unemployment, Calvo wage, cyclical properties

Corresponding author:

Henri R. Sneessens

IRES

Université Catholique de Louvain

3 place Montesquieu

B-1348 Louvain-la-Neuve

Belgium

E-mail: sneessens@ires.ucl.ac.be

\footnotetext{
* We would like to thank participants at the Economic Research Seminar in WHU Koblenz and at the DNB lunch seminar in Amsterdam for valuable comments. The views in the paper represent those of the authors and not necessarily those of the Bank.
} 


\section{Introduction}

One of the main problems of dynamic stochastic general equilibrium (DSGE) models is to reproduce the dynamics of unemployment and wages. A frictional labour market à la Pissarides (2000) in which real wages are determined by Nash bargaining and renegotiated in every period leads to highly volatile and procyclical wages, and too little employment fluctuations (see for instance Merz, 1995, and Andolfatto, 1996). Shimer (2004) shows that it is possible to reproduce a volatility of employment similar to that observed in actual economies, but by imposing full real wage rigidity.

In this paper, we develop an intermediate wage representation (between fully flexible and fully rigid wages) that allows us to obtain suitable business cycle characteristics, in terms of real wage and employment fluctuations. More precisely, we introduce Calvo (1983) contracts (at each period, there is a given probability to renegotiate the wage) within the search unemployment framework. We obtain an equation of real wage rigidities as in Blanchard and Gali (2006), but with microfoundations. The two polar cases mentioned before can be obtained as particular cases of our more general model (when the probability to renegotiate is respectively 1 and 0 ). We show that an average wage contract length of 6 quarters gives satisfactory properties.

\section{The Model}

Our model is a stochastic version of Pissarides's well-known "one-job-one-firm" model (Pissarides, 2000). The economy consists of a measure 1 of risk-neutral, infinitely lived workers and a continuum of risk-neutral, infinitely-lived firms. Workers and firms discount future payoffs at a common exogenous rate $0<\beta<1$. Workers can either be unemployed or employed. An exogenous fraction $s$ of the existing jobs is destroyed in every period (as a result of large negative idiosyncratic productivity shocks) ${ }^{1}$. Search frictions are introduced via a Cobb-Douglas matching function. The number of active firms is determined by a free entry condition. For existing jobs, we assume Calvo contracts with renegotiation probability $\gamma$. For new jobs, we assume that only a fraction $\kappa$ of them can have freely negotiated real wages, the remaining fraction being

\footnotetext{
${ }^{1}$ See Hall (2005) and Shimer (2005) for empirical evidence on the acyclicality of the job destruction rate.
} 
paid the average wage.

\subsection{Value of a job for the firm}

Let $A_{t+j}^{J}\left(x_{t}\right)$ represent the asset value for the firm of a job existing at time $t+j$ (with $j \geq 0$ ) and paid a wage $x_{t}$ that was fixed at time $t$. Let $w_{t}$ represent the economy's average wage at time $t$, while $w_{t}^{*}$ stands for the real wage freely negotiated at time $t$. With this notation, the asset value of a vacant job $A_{t}^{V}$ is then given by:

$$
A_{t}^{V}=-a+\beta \mathrm{E}_{t}\left\{q_{t}\left[\kappa A_{t+1}^{J}\left(w_{t+1}^{*}\right)+(1-\kappa) A_{t+1}^{J}\left(w_{t}\right)\right]+\left(1-q_{t}\right) A_{t+1}^{V}\right\}=0 .
$$

where $a$ is the cost of opening a vacancy and $q_{t}$ the probability that it is filled within the period. The asset value at time $t+j$ (with $j \geq 0$ ) of a job paid a wage that was freely negotiated at time $t$ is determined by:

$$
A_{t+j}^{J}\left(w_{t}^{*}\right)=\left(d_{t+j}-w_{t}^{*}\right)+\beta(1-s) \mathrm{E}_{t+j}\left[\gamma A_{t+j+1}^{J}\left(w_{t+j+1}^{*}\right)+(1-\gamma) A_{t+j+1}^{J}\left(w_{t}^{*}\right)\right],
$$

where $d_{t+j}$ is the job productivity. The last term between the square brackets is the value of the job when the wage is not renegotiated. One obtains the value of a job whose wage is currently renegotiated by starting from (2) with $j=0$ and substituting repetitively for the value of jobs with non-renegotiated wage. This yields:

$$
A_{t}^{J}\left(w_{t}^{*}\right)=\sum_{j=0}^{\infty}[\beta(1-s)(1-\gamma)]^{j} \mathrm{E}_{t}\left[\left(d_{t+j}-w_{t}^{*}\right)+\beta(1-s) \gamma A_{t+j+1}^{J}\left(w_{t+j+1}^{*}\right)\right] .
$$

The asset value of a job started at time $t$ with a wage equal to the average wage $w_{t-1}$ can similarly be obtained and implies ${ }^{2}$ :

$$
A_{t}^{J}\left(w_{t-1}\right)=A_{t}^{J}\left(w_{t}^{*}\right)-\left(w_{t-1}-w_{t}^{*}\right) \sum_{j=0}^{\infty}[\beta(1-s)(1-\gamma)]^{j}
$$

\subsection{Value of a job for the worker}

Let $A_{t+j}^{W}\left(x_{t}\right)$ represent the asset value for the worker of a job held at time $t+j$ (with $j \geq 0$ ) and paid a wage $x_{t}$ fixed at time $t$. The asset value of all future expected earnings of a currently

\footnotetext{
${ }^{2}$ To ensure that no jobs are voluntary destroyed by the firm, we need $A_{t}^{J}\left(w_{t}\right)>0$ for all the wage distribution. We check ex post this condition (see appendix).
} 
unemployed worker is then given by:

$$
A_{t}^{U}=b_{t}+\beta \mathrm{E}_{t}\left\{p_{t}\left[\kappa A_{t+1}^{W}\left(w_{t+1}^{*}\right)+(1-\kappa) A_{t+1}^{W}\left(w_{t}\right)\right]+\left(1-p_{t}\right) A_{t+1}^{U}\right\}
$$

where $b_{t}$ represents an exogenous unemployment benefit and $p_{t}$ is the probability to be hired during period $t$. The asset value at time $t+j$ (with $j \geq 0$ ) of a job paid a wage that was freely negotiated at time $t$ is given by:

$$
A_{t+j}^{W}\left(w_{t}^{*}\right)=w_{t}^{*}+\beta \mathrm{E}_{t+j}\left\{(1-s)\left[\gamma A_{t+j+1}^{W}\left(w_{t+j+1}^{*}\right)+(1-\gamma) A_{t+j+1}^{W}\left(w_{t}^{*}\right)\right]+s A_{t+j+1}^{U}\right\} .
$$

By following the same procedure as before, we obtain the value for a worker of a job whose wage is currently renegotiated:

$$
\begin{aligned}
A_{t}^{W}\left(w_{t}^{*}\right) & =w_{t}^{*} \sum_{j=0}^{\infty}[\beta(1-s)(1-\gamma)]^{j} \\
& +\beta(1-s) \gamma \sum_{j=0}^{\infty}[\beta(1-s)(1-\gamma)]^{j} \mathrm{E}_{t}\left[A_{t+j+1}^{W}\left(w_{t+j+1}^{*}\right)\right] \\
& +\beta s \sum_{j=0}^{\infty}[\beta(1-s)(1-\gamma)]^{j} \mathrm{E}_{t}\left[A_{t+j+1}^{U}\right] .
\end{aligned}
$$

The asset value of a job started at time $t$ with a wage equal to the average wage $w_{t-1}$ can similarly be obtained and implies ${ }^{3}$ :

$$
A_{t}^{W}\left(w_{t-1}\right)=A_{t}^{W}\left(w_{t}^{*}\right)+\left(w_{t-1}-w_{t}^{*}\right) \sum_{j=0}^{\infty}[\beta(1-s)(1-\gamma)]^{j} .
$$

\subsection{Closing the model}

The bargained wage comes from the maximization problem:

$$
\max _{w_{t}^{*}}\left[A_{t}^{W}\left(w_{t}^{*}\right)-A_{t}^{U}\right]^{\xi}\left[A_{t}^{J}\left(w_{t}^{*}\right)\right]^{1-\xi}
$$

where $\xi$ is the worker's bargaining power. That gives:

$$
(1-\xi)\left[A_{t}^{W}\left(w_{t}^{*}\right)-A_{t}^{U}\right]=\xi A_{t}^{J}\left(w_{t}^{*}\right) .
$$

\footnotetext{
${ }^{3}$ To ensure that no jobs are voluntary destroyed by the worker, we need $A_{t}^{W}\left(w_{t}\right)>A_{t}^{U}$ for all the wage distribution. We check ex post this condition (see appendix).
} 
The economy wide average wage $w_{t}$ satisfies:

$$
N_{t} w_{t}=(1-s) N_{t-1}\left[(1-\gamma) w_{t-1}+\gamma w_{t}^{*}\right]+H_{t-1}\left[(1-\kappa) w_{t-1}+\kappa w_{t}^{*}\right]
$$

where $N_{t}$ is the employment level and $H_{t}$ is the number of new jobs (hirings) created at time $t$.

The number of new jobs is defined by the matching function:

$$
H_{t}=\bar{m} V_{t}^{1-\lambda}\left(1-N_{t}\right)^{\lambda}
$$

where $V_{t}$ is the amount of vacancies, $\bar{m}$ is the matching efficiency and $\lambda$ is the elasticity of matches with respect to unemployed. Employment is given by:

$$
N_{t}=(1-s) N_{t-1}+H_{t-1}
$$

Using equation (13) and defining $\delta=\gamma+\frac{H_{t-1}}{N_{t}}(\kappa-\gamma)$, we can rewrite the wage equation (11) as:

$$
w_{t}=(1-\delta) w_{t-1}+\delta w_{t}^{*}
$$

This microfounded equation is similar to the equation of real wage rigidities proposed in Blanchard and Gali (2006). The parameter $\delta$ describes the wage sluggishness. When $\gamma=\kappa=0$, then $\gamma=0$ and the wage is fully rigid. When $\gamma=\kappa=1$, then $\gamma=1$ and the wage is fully flexible (standard Nash bargain). All other combinations give $0<\delta<1$. The probabilities to fill a vacancy and to find a job are respectively given by:

$$
q_{t}=\frac{H_{t}}{V_{t}} \quad \text { and } \quad p_{t}=\frac{H_{t}}{1-N_{t}} .
$$

Finally, the job productivity is represented by the stochastic process:

$$
d_{t}=\bar{d}^{1-\eta} d_{t-1}^{\eta} \exp \left(u_{t}\right)
$$

where $\bar{d}$ is the mean productivity, $\eta$ is the autoregressive parameter, $u_{t}$ is the stochastic shock.

\section{Cyclical Properties}

\subsection{Calibration}

The calibration is displayed in table 1 . We assume a quarterly data model. The discount factor is set to 0.99 , implying a real annual interest rate of $4 \%$. The worker bargaining power is 


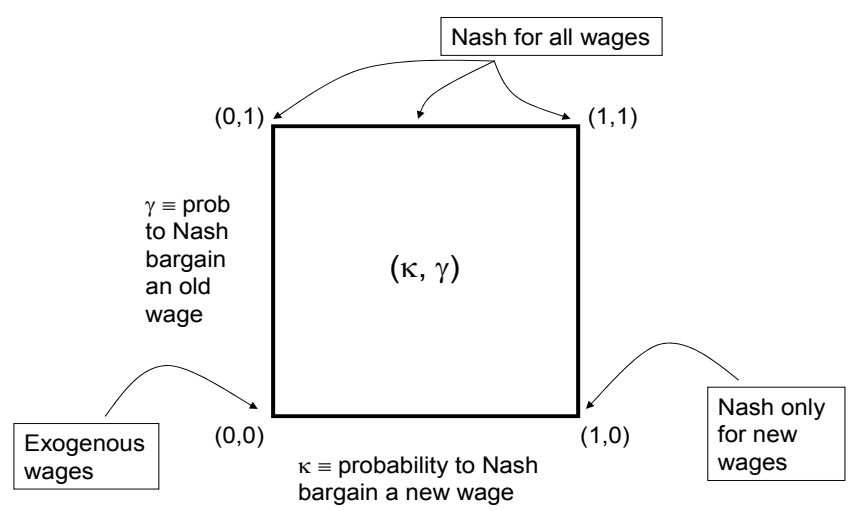

Figure 1: Wage rigidities: different cases

equal to the elasticity of the matching function (Hosios, 1990, condition) and set to 0.5 (see also Shimer, 2004). From Hall (2005) empirical evidence (on US monthly data), we compute a quarterly job destruction rate of $4 \%$ and, by simplicity, we assume no unemployment benefits. We choose the opening cost of a vacancy and the matching efficiency so as to satisfy a steady state unemployment rate of $5.7 \%$ (US average over the last decades) and an equivalent number of vacancies (labour market tightness normalized to 1). Finally, the steady state job productivity is normalized to 1 and the autoregressive parameter is set to 0.9 . The stochastic shock is drawn from a $N(0, \sigma)$ distribution and sigma is set to 0.015 . The parameters $\kappa$ (for new jobs) and $\gamma$ (for old jobs) governing the wage rigidities are free to move between 0 and 1 . Figure 1 illustrates the different possibilities and special cases for $(\kappa, \gamma)$.

\subsection{Simulations}

We focus on the implications of the model for the relative standard deviation and the correlation with output of unemployment and wages. Figure 2 reproduces the values obtained for the

\begin{tabular}{lrr|lr|lr|ll}
\hline & & & & & \\
Symbol & Value & Symbol & Value & Symbol & Value & Symbol & Value \\
\hline $\bar{d}$ & 1 & $\beta$ & 0.99 & $s$ & 0.04 & $a$ & 0.87 \\
$\eta$ & 0.9 & $\lambda$ & 0.5 & $b_{t}$ & 0 & $\bar{m}$ & 0.66 \\
$\sigma$ & 0.015 & $\xi$ & 0.5 & & & & \\
\hline
\end{tabular}

Table 1: Numerical parameter values 

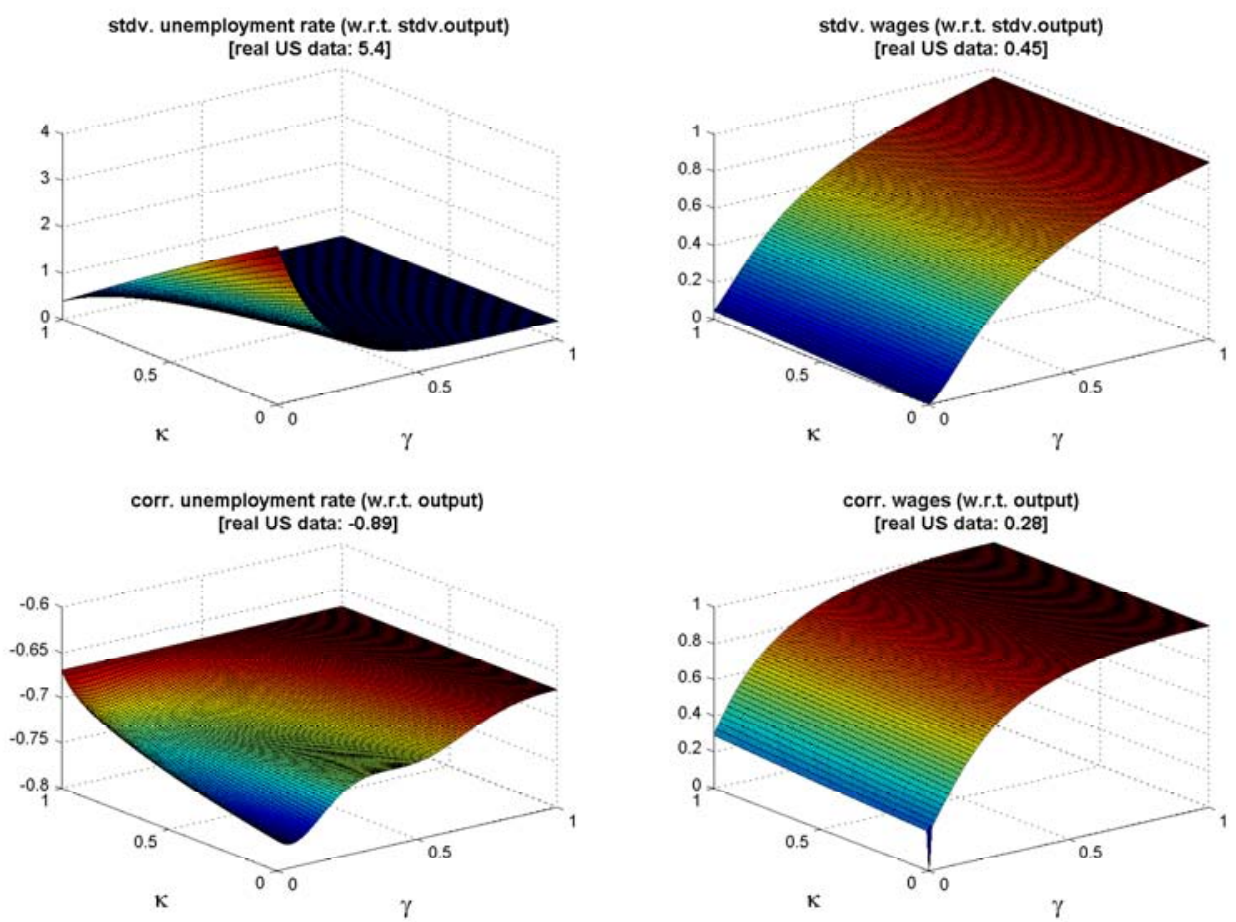

Figure 2: Labour market cyclical properties

Simulated data: all series are HP filtered with a 1600 weight, $\kappa$ : probability to Nash bargain a new wage, $\gamma$ : probability to Nash bargain an old wage, output $\equiv d_{t} N_{t}$. Real US data: all series from 1970 to 2004 and HP filtered with a 1600 weight, unemployment rate: quarterly average of seasonally adjusted monthly series constructed by the Bureau of Labor Statistics (BLS), wage: real hourly compensation in the non-farm business sector constructed by the BLS, output: non-farm business sector real output constructed by the BLS. 
different values of $\kappa$ and $\gamma$; it also gives the corresponding statistics computed from real US data.

Changing $\gamma$ changes the flexibility of wages paid on existing jobs, while $\kappa$ affects the flexibility of wages on new jobs. We see (right panels of figure 2) that changing $\kappa$ has little effect on the cyclical properties of average wages. This is because new wages only represent, on average, $4 \%$ of all the wages. To have a realistic representation for the wage dynamics (low volatility and correlation with output), we therefore need a small, but strictly positive, $\gamma$. However, a decrease in $\gamma$ has no effects on the unemployment cyclical properties as long as $\kappa=1$. It is indeed the amount of wage flexibility at the margin, i.e. for newly created jobs, that is crucial for job creation and unemployment fluctuations. To obtain a high volatility of unemployment, we thus need both a low value of $\gamma$ and a low value of $\kappa$.

To further investigate the implications of different combinations of the parameter values, we computed the distance between the real US statistics and the model statistics for different values of $\gamma$ and $\kappa$. We give the same weight to each of the four statistics and minimize the sum of the squared distances. Figure 3 shows that the total distance is minimum for $\kappa=0$ and $\gamma=0.15$, that is all new jobs start at the average wage and the average wage contract duration is about six quarters, which is not too unrealistic for wage contracts.

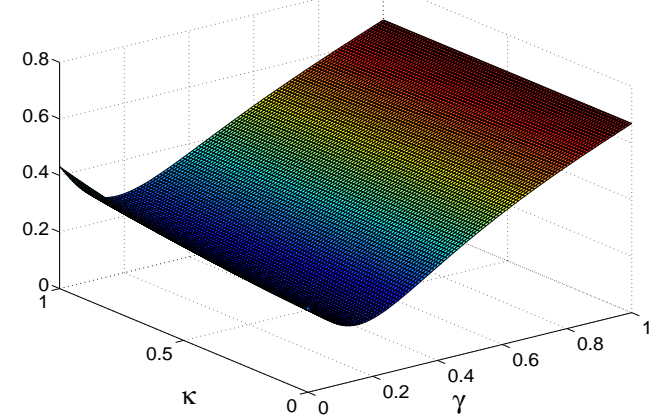

Figure 3: Distance between real and simulated statistics, depending on $\kappa$ and $\gamma$ 


\section{References}

Andolfatto D., 1996, Business Cycles and Labor-Market Search, American Economic Review, $86,112-132$.

Blanchard O. and J. Gali, 2006, Real Wage Rigidities and the New Keynesian Model, conference volume "Quantitative evidence on price determination", Journal of Money, Credit and Banking. Calvo G., 1983, Staggered Prices in a Utility-Maximizing Framework, Journal of Monetary Economics, 12, 383-398.

Hall R., 2005, Job Loss, job Finding, and Unemployment in the U.S. Economy over the Past Fifty Years, NBER Macroeconomics Annual 2005, 101-137.

Hosios A., 1990, On the Efficiency of Matching and Related Models of Search and Unemployment, Review of Economic Studies, 57, 279-298.

Mertz M., 1995, Search in the Labor Market and the Real Business Cycle, Journal of Monetary Economics, 36, 269-300.

Pissarides C., 2000, Equilibrium Unemployment Theory, The MIT Press, Cambridge.

Shimer R., 2004, The Consequences of Rigid Wages in Search Models Journal of the European Economic Association (Papers and Proceedings), 2, 469-479.

Shimer R., 2005, The Cyclicality of Hires, Separations, and Job-to-Job Transitions, Federale Reserve Bank of St. Louis Review, 87(4), 493-507. 


\section{Appendix}

\section{Definition}

Let $\hat{\hat{w}}_{t}$ be the lowest wage the worker accepts to receive at time $t$, given by $A_{t}^{W}\left(\hat{\hat{w}}_{t}\right)=$ $A_{t}^{U}$. Let $\hat{w}_{t}=\min \left[\hat{w}_{t-1}, w_{t-1}, w_{t}^{*}\right]$.

\section{Proposition 1}

$\hat{\hat{w}}_{t}<\hat{w}_{t} \Longrightarrow$ there is no voluntary match destruction by the worker

Definition

Let $\overline{\bar{w}}_{t}$ be the highest wage the firm accepts to pay at time $t$, given by $A_{t}^{J}\left(\overline{\bar{w}}_{t}\right)=0$.

Let $\bar{w}_{t}=\max \left[\bar{w}_{t-1}, w_{t-1}, w_{t}^{*}\right]$.

\section{Proposition 2}

$\bar{w}_{t}<\overline{\bar{w}}_{t} \Longrightarrow$ there is no voluntary match destruction by the firm

By checking ex post that $\hat{\hat{w}}_{t}<\hat{w}_{t}$ and $\bar{w}_{t}<\overline{\bar{w}}_{t} \forall t$, we know by Proposition 1 and Proposition 2 that there is no incentive for both the worker and the firm to destroy the match. 